\title{
Dnmt3b Prefers Germ Line Genes and Centromeric Regions: Lessons from the ICF Syndrome and Cancer and Implications for Diseases
}

\author{
Emma L. Walton, Claire Francastel * and Guillaume Velasco \\ CNRS UMR7216, Epigenetics and Cell Fate, Université Paris Diderot, Bâtiment Lamarck, 4ème étage \\ Case Courrier 7042, 35 rue Hélène Brion, 75205 Paris, France; \\ E-Mails: ewalton86@googlemail.com (E.L.W.); guillaume.velasco@univ-paris-diderot.fr (G.V.) \\ * Author to whom correspondence should be addressed; E-Mail: claire.francastel@univ-paris-diderot.fr; \\ Tel.: +33-1-5727-8918; Fax: +33-1-5727-8910.
}

Received: 18 May 2014; in revised form: 18 July 2014 / Accepted: 21 August 2014 /

Published: 5 September 2014

\begin{abstract}
The correct establishment and maintenance of DNA methylation patterns are critical for mammalian development and the control of normal cell growth and differentiation. DNA methylation has profound effects on the mammalian genome, including transcriptional repression, modulation of chromatin structure, $\mathrm{X}$ chromosome inactivation, genomic imprinting, and the suppression of the detrimental effects of repetitive and parasitic DNA sequences on genome integrity. Consistent with its essential role in normal cells and predominance at repetitive genomic regions, aberrant changes of DNA methylation patterns are a common feature of diseases with chromosomal and genomic instabilities. In this context, the functions of DNA methyltransferases (DNMTs) can be affected by mutations or alterations of their expression. DNMT3B, which is involved in de novo methylation, is of particular interest not only because of its important role in development, but also because of its dysfunction in human diseases. Expression of catalytically inactive isoforms has been associated with cancer risk and germ line hypomorphic mutations with the ICF syndrome (Immunodeficiency Centromeric instability Facial anomalies). In these diseases, global genomic hypomethylation affects repeated sequences around centromeric regions, which make up large blocks of heterochromatin, and is associated with chromosome instability, impaired chromosome segregation and perturbed nuclear architecture. The review will focus on recent data about the function of DNMT3B, and the consequences of its deregulated activity on pathological
\end{abstract}


DNA hypomethylation, including the illicit activation of germ line-specific genes and accumulation of transcripts originating from repeated satellite sequences, which may represent novel physiopathological biomarkers for human diseases. Notably, we focus on cancer and the ICF syndrome, pathological contexts in which hypomethylation has been extensively characterized. We also discuss the potential contribution of these deregulated protein-coding and non-coding transcription programs to the perturbation of cellular phenotypes.

Keywords: DNA methylation; DNMT3B; germ line genes; centromeric repeats; ICF syndrome; cancer

\section{An Introduction to DNA Methylation}

DNA methylation was the first described epigenetic mark of eukaryotic genomes shown to affect gene expression, and perturbations to this process were rapidly suspected to cause aberrant transcription in physiopathological situations like aging and cancer [1].

DNA methylation within mammalian genomes is found mainly within the context of CpG dinucleotides. Recent advances in high throughput sequencing have enabled the generation of base pair resolution maps of DNA methylation in an array of different cell types and developmental stages. These maps have unveiled the uneven distribution of DNA methylation, in particular with respect to CpG density [2,3]. They also highlighted the largely context-specific deposition of DNA methylation. The bulk of mammalian genomes is at least partially methylated with the exception of short, CG-rich sequences termed $\mathrm{CpG}$ islands, found in around two thirds of promoters [4]. These findings imply that most proximal transcriptional control elements are unmethylated, whereas gene bodies, transposons, and repetitive elements are largely methylated in somatic cells [5]. DNA methylation has been implicated in transcriptional repression [6,7], the control of alternative splicing [8], regulation of transcription from alternative promoters within gene bodies [9], and the inhibition of transposition and mitotic recombination at repetitive sequences [10,11]. It is also involved in $\mathrm{X}$ chromosome inactivation in female cells and in the control of allelic-specific expression during genomic imprinting [12-14].

DNA methylation is established and maintained by three enzymes with DNA methyltransferase activity, all of which are essential for life [10,15]. Semi-conservative DNA replication provides the opportunity for patterns of existing methylation to be copied onto nascent daughter strands. This is achieved by the activity of the maintenance methylation enzyme DNMT1 [10], which, in complex with its cofactor UHRF1, recognizes and binds to hemi-methylated DNA and accurately copies existing patterns of methylation [16,17]. DNMT1 is ubiquitously expressed during development, in contrast with the de novo methyltransferases DNMT3A and DNMT3B, which are highly expressed in embryonic stem cells and are subsequently down-regulated during development in most tissues. These enzymes, in concert with their catalytically inactive cofactor DNMT3L, or alone, depending on the developmental context $[18,19]$, ensure the establishment of methylation patterns from an unmethylated template during early development and thus play an essential role in the correct establishment of methylation patterns [20]. In addition, recent studies have shown a role for de novo methyltransferases 
in the maintenance of methylation patterns at loci such as germ line genes and repetitive elements, suggesting that these enzymes participate in the silencing of these regions in many cellular and developmental contexts [21-23].

\section{DNMT3B: A de novo Methyltransferase with Many Isoforms}

DNMT3B shares structural organization with DNMT3A. Both proteins possess a variable N-terminal domain, which is followed by a moderately conserved PWWP (Pro-Trp-Trp-Pro) domain [24]. This domain, although it has little or no DNA binding activity, is required for the recruitment of both enzymes to heterochromatin nuclear domains, which occurs through interactions with heterochromatin proteins like HP1 [25]. The PWWP domain is followed by a highly conserved cysteine-rich zinc finger-binding domain called the ADD domain (ATRX-DNMT3-DNMT3L), which shares homology with the plant homeodomain (PHD) and is involved in binding to histone tails [26]. The ADD domain binds to $\mathrm{H} 3$ tails unmethylated at lysine 4 (H3K4me3) leading to the preferential methylation of DNA bound to loci with this chromatin state. All DNMTs possess a highly conserved catalytic domain in their $\mathrm{C}$ terminus that contains six amino acid motifs, which are involved in distinct steps of the catalytic mechanism including enzymatic catalysis, DNA binding, and S-adenosyl-methionine cofactor binding. Both DNMT3A and DNMT3B can be expressed as alternatively spliced variants in which some of the catalytic motifs or their spacing are disrupted, thus affecting the integrity of the catalytic domain [27-33].

The DNMT3B human gene has 23 exons. The full length DNMT3B1 isoform is strongly expressed during early development and is barely detectable in differentiated cells. Many isoforms have been described for DNMT3B, which result from alternative splicing as mentioned above and/or alternative promoter usage [15]. Notably, the alternative splicing of exons 10 and 11 and exons 21 to 23 within the catalytic domain creates an array of different isoforms, many of which are expressed in differentiated cells, albeit at low levels [20,34,35]. DNMT3B2 lacks Exons 10 and 11 but retains the catalytic domain, whereas DNMT3B3, in addition to Exons 10 and 11, lacks Exons 21 and 22 of the catalytic domain. DNMT3B3 is the most predominant form in somatic cells, although other isoforms are also present, including DNMT3B4 and DNMT3B5, which encode truncated proteins missing parts of the catalytic domain. DNMT3B1 and DNMT3B2 contain all six highly conserved amino acid motifs of the catalytic domain and are enzymatically active. Although DNMT3B3, DNMT3B4, and DNMT3B5 are catalytically inactive, these isoforms may nonetheless interfere with the action of catalytically competent DNMT3B with which they co-exist in the cell, notably in particular pathogenic contexts [29,30]. These inactive isoforms may still retain DNA-binding activity and thus may compete with catalytically active DNMT3B for target binding. Chedin and colleagues demonstrated recently that these variants bind to catalytically competent de novo DNMTs and regulate their activity; DNMT3B3 stimulates the basal activity of DNMT3 enzymes, but partially inhibits the stimulatory effect of DNMT3L, whereas DNMT3B4 significantly impairs de novo methylation [27]. 


\section{Genomic Loci Affected by DNMT3B Loss of Function.}

\subsection{Centromeric and Pericentromeric DNA Repeats}

With DNA methylation being non-randomly distributed, and with two de novo DNA methyltransferases being implicated in establishment of methylation profiles, one can assume that the enzymes themselves are not randomly recruited to the genome. The identification of genomic regions preferentially methylated by DNMT3B has been largely inferred from studies involving the targeted disruption of the gene in mice and from the analysis of molecular defects observed in human diseases. The first genomic regions shown to be affected by loss of DNMT3B function were not protein-coding regions, but non-coding repetitive elements found around centromeres [20,36].

In most higher eukaryotes, these regions are assembled on large arrays of tandemly repeated DNA sequences, which can be divided into two distinct functional domains [37]; the centromere per se, that serves as the point of assembly for the kinetochore, and flanking heterochromatin domains, thought to protect the centromere and ensure sister chromatid cohesion [38]. In the mouse, pericentromeric domains are made up of $\mathrm{A} / \mathrm{T}$ rich $234 \mathrm{bp}$ major satellite repeats, and adjacent centromeric regions comprise $120 \mathrm{bp}$ minor satellite repeats [39]. The contribution of these sequences to the genome is substantial, with major satellite repeats representing approximately $3 \%$ of the mouse genome and minor satellite repeats representing approximately $0.45 \%$ of the genome [40]. In humans, centromeric regions contain 171-bp AT-rich $\alpha$-satellite motifs. The size and structure of pericentromeric regions varies between chromosomes, and three types of satellite repeats account for about $4 \%-5 \%$ of the human genome. Satellite type I are short AT-rich sequences found at pericentromeric regions of most chromosomes. Type II and type III satellites are made of a $5 \mathrm{bp}$ GGAAT repeat unit possibly found on all chromosomes but unevenly distributed over up to several megabases, where they form heterochromatin blocks in pericentromeric regions of certain chromosomes like chromosomes 1, 9, 16 and heterochromatin of chromosome Y [41].

Molecular analysis of mutant mouse embryos lacking Dnmt3b and those lacking Dnmt3a have suggested that Dnmt3b is specifically required for the methylation of centromeric minor satellites whereas Dnmt3a preferentially methylates pericentromeric heterochromatin [20]. The partial loss of function of DNMT3B in patients with the ICF syndrome (see below) is associated with the hypomethylation of pericentromeric satellite type II and III repeats (Sat II, Sat III). The origin of this discrepancy between mouse and human is unclear. Indeed, only general similarities can be drawn from the centromeric regions of the different eukaryotes, such as the abundance of simple or complex repeats, the association of the centromeres with surrounding heterochromatin [42] and the presence of a histone variant, CENP-A, that partially replaces histone H3 in centromeric nucleosomes [43]. In addition, there is a widespread lack of sequence conservation of centromeric and pericentromeric regions throughout the phylogeny, and no conservation of sequence or chromatin organization or even organization in the nuclear space seems to exist between centromeric murine minor satellites and pericentomeric human Sat II and III repeats. Centromeric regions were long considered to be transcriptionally repressed, mainly because they are methylated in somatic cells and because they are surrounded by large blocks of heterochromatin assembled at pericentromeric regions; however, transcripts arising from both centromeric and pericentromeric regions have been characterized in a 
multitude of organisms and in a variety of cell types and developmental stages (reviewed by $[44,45]$ ). These transcripts are integral parts of centromeric and pericentromeric complexes and participate in the assembly and function of centromeres and its surrounding heterochromatin [46-48]. Whether they are implicated in the selective recruitment of DNMT3B at murine centromeric and human pericentromeric repeats remains to be tested.

\subsection{Germ Line Genes}

The discovery of additional loci affected by the loss or reduced function of DNMT3B awaited the detailed transcriptional analysis of mouse embryos deficient or partially deficient in Dnmt3b, which revealed the aberrant activation of many genes, of which the most deregulated are normally mainly expressed in the germ line $[49,50]$. Promoter hypomethylation of these germ line genes strongly correlates with their illicit expression in somatic tissues, consistent with DNA methylation playing the principal role in their transcriptional repression in somatic cells [51,52]. Dnmt3b is present at the promoter regions of several germ line genes in mouse embryonic fibroblasts [50] suggesting that it plays the principal role in the establishment of DNA methylation at these genes during early development. Dnmt3b may even play a role in the maintenance of methylation at a subset of these genes because their methylation status is preserved in the absence of the maintenance enzyme Dnmt1 [23]. Meehan and colleagues have recently demonstrated that the expression of another set of germ line genes involved in genome defense against transposable elements in developing germ cells is also exclusively dependent on DNA methylation mediated by Dnmt3b [53]. Thus DNA methylation is critical for the silencing of a subset of germ line genes and may be the predominant regulatory mechanism at these loci.

\subsection{Other DNA Repeats}

In humans, DNMT3B appears to be the major enzyme involved in the de novo methylation of repetitive sequences located in pericentromeric constitutive heterochromatin. The non-satellite repeats NBL2 and D4Z4, which are aberrantly methylated in particular pathological contexts [54,55], are also hypomethylated in DNMT3B deficient cells from ICF patients, suggesting a major role for this enzyme at other repeats with hallmarks of heterochromatin [56]. Likewise, facultative heterochromatin on the inactive $\mathrm{X}$ chromosome in cells from female patients and Alu repeats that are widely distributed throughout the human genome are undermethylated in ICF cells [57]. Perhaps more striking is the hypomethylation of sub-telomeric repeats in these patients [58]. However, human telomeres and adjacent subtelomeric regions are packaged as heterochromatin in many organisms and share many epigenetic marks with pericentromeric regions. Human subtelomeric regions are rich in CG sites and these regions are heavily methylated in somatic cells [59].

Thus, in humans, DNMT3B loss of function appears to mainly affect methylation at DNA repeats within or proximal to large heterochromatin domains, consistent with DNA methylation being a hallmark of heterochromatin and DNMT3B playing the principal role in its establishment and maintenance. In the mouse, Dnmt3b cytologically accumulates on constitutive heterochromatin nuclear domains formed by pericentromeric repeats and Dnmt3b loss of function is linked to its delocalization from these domains $[60,61]$. In this context, it is difficult to understand how this may specifically 
affect methylation at murine centromeric repeats that form distinct subnuclear domains at the periphery of heterochromatin compartments [37]. Thus, it is possible that human pericentromeric and mouse centromeric repeats share binding sites for factors that are important for the recruitment of Dnmt3b.

\section{Dnmt3b and Development}

\subsection{Early Development}

DNA methylation is highly dynamic during development and patterns of DNA methylation are reprogrammed genome-wide at two different stages: once in pre-implantation embryos and again at a later time point in developing germ cells (Figure 1).

Figure 1. Dynamics of DNA methylation at germ line genes and satellite repeats during the mammalian life cycle. DNA methylation is reprogrammed twice during development; first during the preimplantation blastocyst and again in primordial germ cells. Although germ line genes and minor satellite centromeric repeats are heavily methylated in somatic cells and in germ cell precursors (black circles), they are hypomethylated in primordial germ cells, gametes and in cells of the inner cell mass of the blastocyst (white circles). Global DNA methylation levels are indicated on the y-axis and are shown in blue for the paternal genome and in pink for the maternal genome. DNA methylation at centromeric repeats and germ line genes is established specifically by Dnmt3b during the wave of remethylation that begins around the time of implantation.

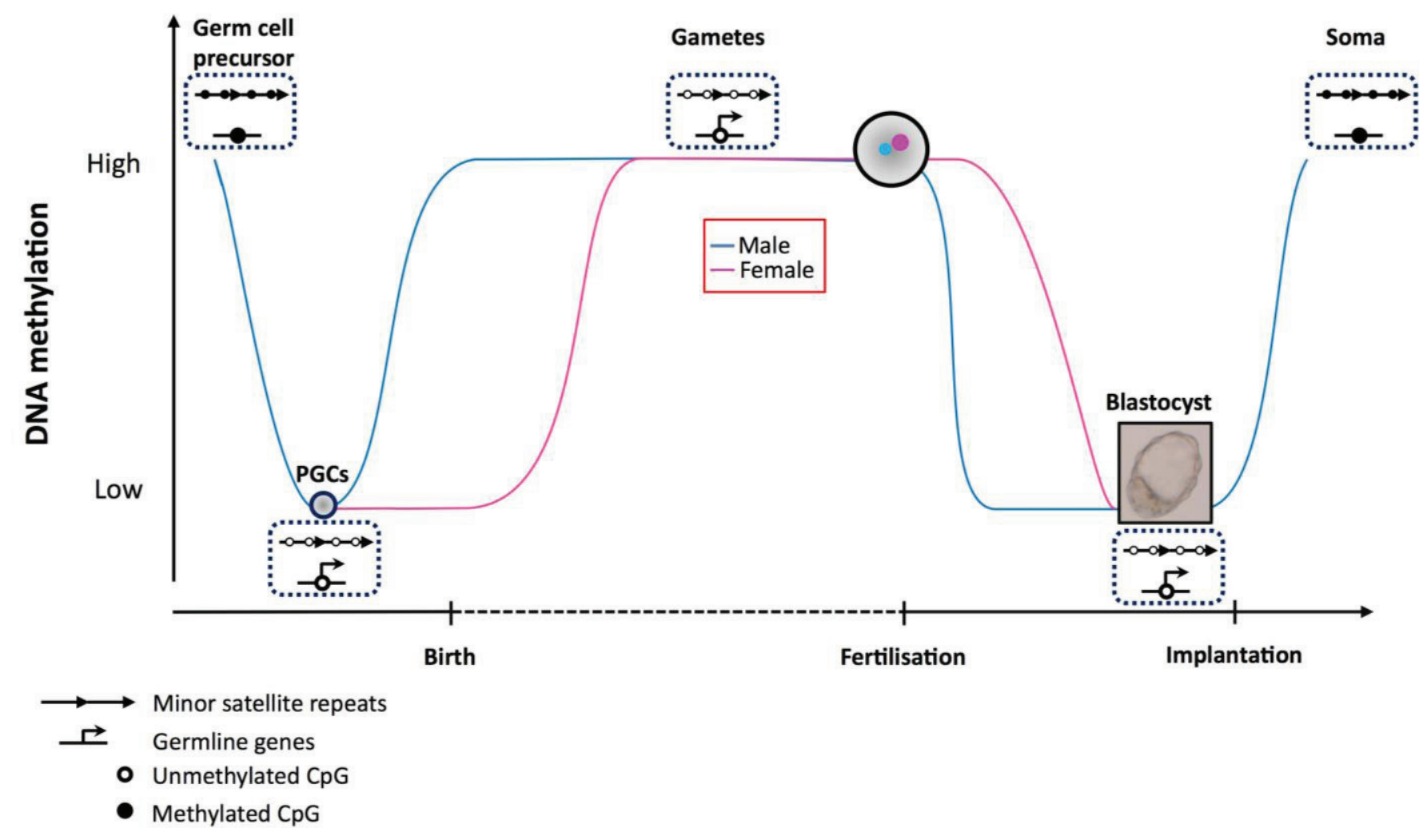


In the mouse, a wave of methylation erasure occurs in the early embryo [62]. Enzymes of the ten-eleven-translocation (Tet) family have been shown to facilitate DNA replication-independent erasure of $\mathrm{CpG}$ methylation by converting 5 -methylcytosine $(5 \mathrm{mC})$ to 5 -hydroxymethylcytosine $(5 \mathrm{hmC})[63,64]$. The development of techniques that discriminate $5 \mathrm{mC}$ and $5 \mathrm{hmC}$ has enabled the role of Tet enzymes and that of this potentially new epigenetic mark to be extensively studied in development and disease over the past few years [65,66]. After this step of demethylation, new patterns of DNA methylation are re-established shortly after implantation in the developing epiblast [62]. This de novo methylation is required for the differentiation of the epiblast, as shown by the lethality at gastrulation of embryos deficient of both de novo methyltransferases Dnmt3a and Dnmt3b [20,67]. However, DNA methylation is not required for establishment and maintenance of naïve pluripotency because embryonic stem cells (ESC) can be established from embryos deficient of the three Dnmts (TKO ESC) [68]. This contrasts with the rapid apoptosis induced by hypomethylation in somatic cells [69].

In murine embryonic pluripotent cells captured in culture, ESC derived from the inner cell mass (ICM) or the late epiblast of post-implantation embryos (EpiSC) do not display quantitative differences in DNA methylation [70]. However, in line with the observed upregulation of the de novo methyltransferases Dnmt3a and Dnmt3b, a bias towards methylation of high CpG island promoters in EpiSC was recently described [71]. However, a comparison of EpiSCs and late epiblast cells revealed that the in vitro and "in embryo" cells show a strikingly different promoter methylation profile [71]. Not surprisingly, these data highlight that the deposition of DNA methylation is greatly affected by culture conditions and that external factors are missing when embryonic stem cells are dissociated and explanted in vitro. Along the same lines, when cultured in serum conditions, mouse ESCs fluctuate between a naive ICM-like state and a primed epiblast-like state. However, recent reports have shown that ESCs cultured with inhibitors of the mitogen-activated protein kinase (MAPK) and glycogen synthase kinase 3 pathways (2i), that more faithfully recapitulate the naive state of ICM cells, are significantly more hypomethylated than their serum-cultured counterparts, consistent with low methylation levels found in pre-implantation blastocysts [72,73].

These systems have been widely used to decipher when and where on the genome DNA methylation is established early in development. Major changes occur at the transition from the blastocyst to the post-implantation epiblast, where DNA methylation is primarily targeted to repress the germ line expression program and lineage-affiliated genes such as haematopoietic genes [49]. Dnmt3b catalyses this de novo methylation during early embryogenesis, and the absence of DNA methylation leads to ectopic gene activation in the embryo. Methylation at centromeric sequences in ES cells has been more difficult to dissect. In serum-cultured ESCs, many repetitive DNA elements, including centromeric repeats, are highly methylated as they are in somatic cells [74], although, female ESCs are remarkably hypomethylated compared to their male counterparts at both repetitive sequences and unique sequences [75]. In " $2 \mathrm{i}$ " conditions, maintenance of the naive state appears to be linked to the expression of Prdm14, that acts, at least in part, through down-regulation of Dnmt3b [73,76], recapitulating the low abundance of de novo Dnmts described for the ICM in vivo. Therefore, repetitive elements, in particular centromeric sequences, are probably hypomethylated in the ICM of pre-implantation embryos. 
DNA methylation is reprogrammed a second time in developing germ cells [77]. The majority of the genome is subject to methylation erasure, including imprinted regions and repetitive elements such as centromeric repeats [78,79]. Demethylation enables the activation of the germ line specific program, which as we have seen is largely controlled by DNA methylation. Subsequently, methylation is established with different kinetics in the male and female germ line at time points where the abundance of Dnmt3b is high [80]. However, both germ line genes, which are essential for the establishment of the germ line program, and pericentromeric and centromeric repeats, seem to be protected from this de novo methylation in the germ line [81]. Thus, in terms of DNA methylation at these sequences, germ cells closely resemble the pre-implantation blastocyst.

\subsection{Targeting Dnmt3b during Development}

As mentioned above, most $\mathrm{CpGs}$ outside $\mathrm{CpG}$ islands and regulatory elements are methylated in somatic cells in contrast to the majority of $\mathrm{CpG}$ islands that remain unmethylated throughout development. However, $\mathrm{CpG}$ methylation is highly dynamic. Although variation may occur stochastically during development and lineage specification, certain $\mathrm{CpG}$ islands become selectively methylated, raising the question of how this selectivity is achieved [2,3,82].

Classic studies established that the unmethylated state of promoter $\mathrm{CpG}$ islands is strongly influenced by transcription factor binding. For instance, $\mathrm{CpG}$ islands can acquire methylation following deletion or mutation of promoter Sp1 binding sites [83,84]. Lienert et al. used an approach in which various promoter fragments were targeted to the same genomic insertion site in ESCs to show that DNA methylation is primarily dictated by cis-acting sequences and they identified autonomous methylation determining regions (MDRs) that reside within promoter elements [85]. DNMT enzymes themselves may have a preference for particular DNA sequences flanking target CpG sites [86]. Hervouet and colleagues used transcription factor arrays to systematically identify transcription factors that interact with Dnmt3b [87]. Among these factors, the E2F6 transcriptional repressor is required for the silencing of a subset of germ line genes in somatic cells through the recruitment of Dnmt3b at their promoter region [50] or other repressor complexes in ESCs [88].

Given the lack of sequence conservation of centromeric repeats amongst species, it is highly likely that other mechanisms besides DNA sequence are involved in the targeting of de novo methylation to these regions. Indeed, DNMT3B interacts with the centromeric-specific protein CENP-C, which appears to be important for its recruitment to centromeric regions [89]. In addition, there is overwhelming evidence for crosstalk between DNA methylation and chromatin environment. Perhaps the most striking example of this interplay is the inverse correlation between DNA methylation and H3K4 methylation $[2,4]$. The interaction of the ADD domain with the histone H3 tail is allosterically inhibited by H3K4 methylation [26], thus explaining this association.

The lymphoid-specific helicase LSH (HELLS) is also emerging as a key factor that may be involved in crosstalk between chromatin environment and the establishment of DNA methylation. LSH is a member of the SNF2 family of helicases that are involved in chromatin remodeling [90]. Although mouse embryos lacking Lsh are viable, they show hypomethylation at single copy genes and repeat sequences [91,92]. Genome wide analysis of methylation in cells deficient in Lsh has since documented the severe extent of this hypomethylation $[93,94]$ and has led to the proposition that Lsh 
may be involved in the recruitment of DNMTs. Specifically, Lsh has been proposed to be involved in the recruitment of Dnmt3b, for example, to the stem cell genes promoter during differentiation of ESCs [95]. This mechanism predicts that $\mathrm{Lsh}^{-/}$and Dnmt3b ${ }^{-/-}$cells should have similar molecular defects. Indeed, DNA methylation defects in these mutants are strikingly similar [96], notably at particular repeat classes including centromeric repeats. However, hypomethylation at long terminal repeat (LTR) endogenous retroviruses (ERVs) is more severe in $\mathrm{Lsh}^{-/-}$cells than in $\mathrm{Dnmt} 3 \mathrm{~b}^{-/-}$cells, suggesting that Lsh participates in DNA methylation at particular sequences independently of Dnmt3b [97].

In the developing germ line, small non-coding RNAs are important for the establishment of DNA methylation at transposable elements [98]. Non-coding RNAs that are complementary to the rDNA promoter may also mediate the de novo methylation of rRNA genes [99]. Grummt and colleagues showed that a $120 \mathrm{nt}$ stretch of this promoter-associated RNA interacts with the transcription factor TTF-1, forming a DNA:RNA triplex structure that is recognized by DNMT3B. Small non-coding RNA (ncRNA) transcribed from pericentromeric regions are involved in the establishment of heterochromatin, through guiding associated factors, in fission yeast [100]. Although no evidence for such siRNA exists in mammals, long ncRNA transcribed from murine centromeric and pericentromeric regions may represent one of the many pathways that regulate heterochromatin maintenance and assembly in mammals, possibly through directing centromere- and heterochromatin-associated proteins [46-48]. Therefore, it is conceivable that such non-coding RNA may also be involved in the targeting of de novo methylation to these regions in mammals.

\section{DNMT3B and Disease}

Given the pivotal role that DNA methylation plays during development to regulate gene expression, it comes as no surprise that aberrant patterns of methylation are associated with many human diseases [101]. These may involve isolated events, such as loss of imprinting or changes to the copy number of methylatable trinucleotide repeats, or may entail more global events involving the substantial loss of DNA methylation that is observed in particular immune system disorders including systemic lupus erythematosus and most human cancers [102]. Defects in methylation are associated with a diverse range of clinical outcomes, including intellectual disability, immunodeficiency, autoimmunity, obesity, malignancy, and muscular dystrophy [103]. In cancer, epigenetic changes constitute a highly frequent, arguably invariant hallmark, and cooperate with genetic changes to drive cellular transformation [104]. Perturbations to DNMT enzymes often cause such changes, and the hypomethylation of germ line genes and centromeric regions are common features of cancer cells. Mutations in the DNMT genes are rare in cancer cells, but over-expression of DNMTs is widely described and may partly explain the hypermethylation phenomenon [35]. More recently, splice variants of DNMT3B transcripts have been detected in a wide range of cancer cell lines [28,30,31]. These variants lead to perturbed patterns of methylation which in turn result in the abnormal up or down-regulation of genes. Similarly, in the Immunodeficiency with Centromeric instability and Facial anomalies (ICF) syndrome, germ line mutations in DNMT3B lead to perturbed methylation patterns [36]. Both diseases are characterized by the hypomethylation of satellite repeats and germ line genes, in association with chromosomal instability and perturbed nuclear organization, particularly that of heterochromatin nuclear compartments. 


\subsection{DNMT3B Variants in Cancer}

One of the first reports to establish a clear connection between DNA methylation and cancer came from Feinberg and Vogelstein in 1983, who found hypomethylation in primary tumor samples [105]. Such reports have led to the idea that the genome of cancer cells is globally hypomethylated. DNA repeats, most notably tandem centromeric $\alpha$-satellites, juxta-centromeric (centromere-adjacent) Sat II, interspersed Alu repeats, and long interspersed elements (LINE)-1 repeats, largely account for this global DNA hypomethylation [106]. Examples of promoter specific hypomethylation also exist, most notably at the promoters of germ line genes and oncogenes in various cancer cell lines. This hypomethylation is thought to directly lead to their de-repression $[51,107]$. Germ line genes that are aberrantly expressed in human cancers have also been referred to as "cancer testis" genes because many of them are normally only expressed in the male germ line [108]. Strikingly, this global hypomethylation is concomitant with local hypermethylation, including at the promoter regions of genes involved in cell cycle control or DNA repair, such as p53, Rb, and BRCA1 [104] as well as tumor suppressor genes (TSGs) [109]. Hypermethylation is a major factor in silencing of TSGs and one of the primary inactivating events contributing to tumorigenesis [109].

DNMTs are frequently deregulated in cancers. The general trend appears to be towards the over-expression of these enzymes, which may explain the hypermethylation of TSGs [35]. Nonetheless, somatic loss-of-function mutations in these enzymes have also been described in a wide range of cancer cells. A recent study by Godley and co-workers supports the idea that reduced DNMT3B activity is associated with accelerated tumorigenesis [110]. In this study, inactivation of one allele of Dnmt3b in the context of Myc-driven lymphomagenesis resulted in a dramatic increase in the incidence of lymphoma, coincident with alterations in DNA methylation profiles. This suggests that Dnmt3b can act as a haplo-insufficient tumor suppressor gene in the context of myeloid malignancies. Another possible source of altered patterns of DNA methylation in cancer cells is the expression of splice variants. Godley and colleagues documented over 20 DNMT3B transcripts from various cancer cell lines and primary acute leukemia cells that were alternatively spliced at the 5 ' end of the gene. These variants encode truncated proteins lacking all or part of the C-terminal catalytic domain that may act as dominant-negative isoforms [29]. Indeed, inactive DNMT3B isoforms can alter the enzymatic activity of endogenous full-length DNMT3B in vitro [111]. Ectopic expression of the most commonly expressed variant, DNMT3B7, resulted in perturbed expression programs and methylation profiles, including that of the cancer testes gene MAGEA3. Two studies have also correlated the expression of truncated, catalytically inactive variants of DNMT3B, with the hypomethylation of juxta-centromeric Sat II repeats, confirming that DNMT3B splice variants may impair normal enzyme function in a dominant negative fashion, not only at unique gene loci but also at repetitive sequences $[30,89]$. A direct link between the expression of these isoforms and the hypomethylation of DNMT3B-target germ line genes has not been examined within the context of cancer cells. Nonetheless, many genes that have been described as targets of Dnmt3b in the mouse [49,50], including MAEL, SYCE1, and SYCP1, are aberrantly expressed in human cancers and are listed as cancer testes genes [112]. 


\subsection{Germ Line Mutations in DNMT3B in the ICF Syndrome}

Germ line gene mutations in $D N M T 3 B$ are responsible for the autosomal recessive disease named Immunodeficiency with Centromeric instability and Facial anomalies (ICF syndrome) [20,36,113]. ICF is an incredibly rare disease and was initially distinguished based on cytogenetic abnormalities, namely multi-branching of juxta-centromeric regions of chromosomes 1, 9, and 16, detectable in blood cell cultures of patients presenting with primary immunodeficiency and recurrent infections [114,115]. ICF is a clinically heterogeneous disease, although it is almost invariantly characterized by a severe impairment to humoral immunity involving hypo- or agamma-globulinemia. $\mathrm{B}$ and $\mathrm{T}$ cell numbers and V(D)J recombination are normal [116], suggesting a defect in lymphocyte maturation or activation at late stages. This immunodeficiency leads to recurrent infections that often cause death at a young age. Other clinical features of ICF are present at varying degrees of penetrance and have been extensively reviewed by Hagleitner et al. [117]. Facial dysmorphisms are usually mild and typically involve a flat nasal bridge, hypertelorism (widely spaced eyes), epicanthic folds, macroglossia (enlarged tongue), micrognathia (small jaw), and low set ears. Intellectual impairment and neurological defects may also be present, and include slow cognitive and motor development and psychomotor impairment.

The characteristic chromosomal instabilities that are observed in mitogen-stimulated peripheral blood cultures are used for diagnostic purposes. Decondensation of juxtacentromeric heterochromatin of chromosomes 1, and 16, and to a lesser extent chromosome 9, leads to a wide variety of chromosomal anomalies including chromosome breaks and rearrangements, whole-arm deletions, and often multi-branched chromosomes containing three or more arms of chromosome 1 and 16 joined in the vicinity of the centromere $[114,115,118-120]$. Sat II juxtacentromeric repeats on chromosomes 1 and 16 and Sat III juxtacentromeric repeats on chromosome 9 are hypomethylated in cells from ICF patients, thus mimicking an embryonic-like methylation pattern [121]. Treatment of pro-B cells with the DNA demethylating agent 5-azacytidine, but not other non-demethylating genotoxins, induces ICF-characteristic pericentromeric chromosomal anomalies, suggesting that hypomethylation causes these anomalies [122].

ICF is a genetically heterogeneous disease [123,124]. Fifty to $60 \%$ of cases are explained by mutations in DNMT3B, referred to as ICF1 patients. All affected individuals are homozygotes or compound heterozygotes, mostly for mutations in the C-terminal portion of the protein that contains the catalytic domain [125]. This suggests that ICF is related to impairment in DNA methyltransferase activity and not some other function of DNMT3B. Some residual enzymatic activity is undoubtedly indispensable for survival however, because nonsense mutations are only ever found as compound heterozygotes and complete loss of DNMT3B function is likely embryonic lethal in humans as it is in mice [20]. ICF mutations cause a broad spectrum of biochemical defects in DNMT3B that impair enzymatic activity, including defects in homo-oligomerisation, S-adenosyl methionine (SAM) binding, SAM utilization, and DNA binding [126].

A proportion of ICF patients possess mutations in the zinc-finger and BTB domain-containing 24 (ZBTB24) gene [127], referred to as ICF2 patients. Most mutations create premature stop codons in ZBTB24 suggesting that ICF2 is caused by loss of function of ZBTB24. ZBTB24 is a member of the ZBTB family of transcription factors that are emerging as key regulators of lymphoid development and 
function (recently reviewed in [128]), however little is known about ZBTB24 itself. Additional cases of ICF remain with no described mutation in either $D N M T 3 B$ or $Z B T B 24$, which have been referred to as ICFX [129]. It was initially believed that cases of ICF not related to mutations in DNMT3B would be caused by mutations in genes that are functionally related to $D N M T 3 B$, for example factors that are important for the recruitment of DNMT3B to its target sites. However, molecular and clinical differences between ICF1, ICF2, and ICFX patients are emerging, which is consistent with the involvement of several pathways. In addition to the characteristic Sat II and Sat III sequences, patients without mutations in DNMT3B also show hypomethylation of centromeric $\alpha$-satellite DNA [123]. We have recently reported that the germ line genes $M A E L$ and SYCE1, which we had identified previously as targets of Dnmt3b in the mouse [50], are hypomethylated and aberrantly expressed in the tissues of ICF1 patients [130]. However, the methylation and expression of these genes was unaffected in uncultured cells from ICF2 and ICFX patients, which suggests that ZBTB24 is not involved in the targeting of DNMT3B to germ line genes and thus is not a simple adaptor of DNMT3B function. Instead, ZBTB24 appears to be involved in targeting DNA methylation to both centromeric and pericentromeric satellite repeats in humans. In the mouse, ectopically expressed Dnmt3b and Zbtb24 are targeted to pericentromeric heterochromatin compartments, independent of pre-existing DNA methylation, whereas this targeting is abolished by mutations found in ICF patients [61,131]. Yet, the impact of Zbtb24 mutations on the methylation of these repeats has not been determined. We also identified two ICFX patients with molecular characteristics somewhere in between an ICF1 type and an ICFX type [130]. Indeed, these patients showed hypomethylation and expression of germ line genes accompanied by the hypomethylation of $\alpha$-satellite DNA. The underlying genetic defect(s) in these patients is likely to be highly informative from a mechanistic perspective regarding the establishment and maintenance of DNA methylation. The function of DNMT3B may be impaired in these patients by intronic mutations that cause changes to alternative splicing, or another factor that is required to target DNMT3B to germ line genes. Alternatively, a situation involving dual impairment to DNMT3B and ZBTB24 can also be envisaged. Altogether, these findings highlight the complex etiology of the disease.

Clinical heterogeneity has recently been documented amongst ICF1, ICF2, and ICFX patients, with ICF1 patients displaying a pronounced impairment in humoral immunity and ICF2 patients showing a high incidence of intellectual disability [129]. The identification of molecular differences amongst the various subtypes will be important for the understanding of these phenotypic differences.

\section{Consequences of Hypomethylation at DNMT3B Targets for Disease}

The hypomethylation of germ line genes and centromeric repeats constitute molecular signatures of the ICF syndrome and cancer (Figure 2) but it is unclear how hypomethylation at these sites create a favorable context for disease. Despite the clear similarities between the molecular signatures of the ICF syndrome and cancer, malignancies have been reported in very few cases in ICF patients [117,132]. In ICF patient cells, in which cell checkpoints appear to be normal [133], it is probable that epigenetic defects alone are not sufficient to drive tumorigenesis. This is consistent with cancer being a "multi-hit" process and the premature death of ICF patients probably does not leave enough time for the subsequent "hits" to occur. 
Figure 2. Hypomethylation of germ line genes and satellite repeats in somatic cells as biomarkers for disease. In cancer, the aberrant expression of alternatively spliced DNMT3B transcripts (DNMT3B*) lead to the hypomethylation of DNMT3B targets, whereas this is caused by germ line mutations in DNMT3B (DNMT3Bm) in the Immunodeficiency Centromeric instability Facial anomalies (ICF) syndrome. As a result, somatic cells from ICF patients or cancer cells show a profile of hypomethylation at germ line genes and centromeric repeats that closely resembles that of ES cells but also gametes. Hypomethylation at these regions is associated with a variety of abnormal nuclear and cellular phenotypes, some of which are common signatures between ICF and cancer cells. Germ line genes and centromeric repeats are represented as in Figure 1. Methylated $\mathrm{CpG}$ residues are shown as filled circles and unmethylated $\mathrm{CpG}$ residues are shown as open circles.

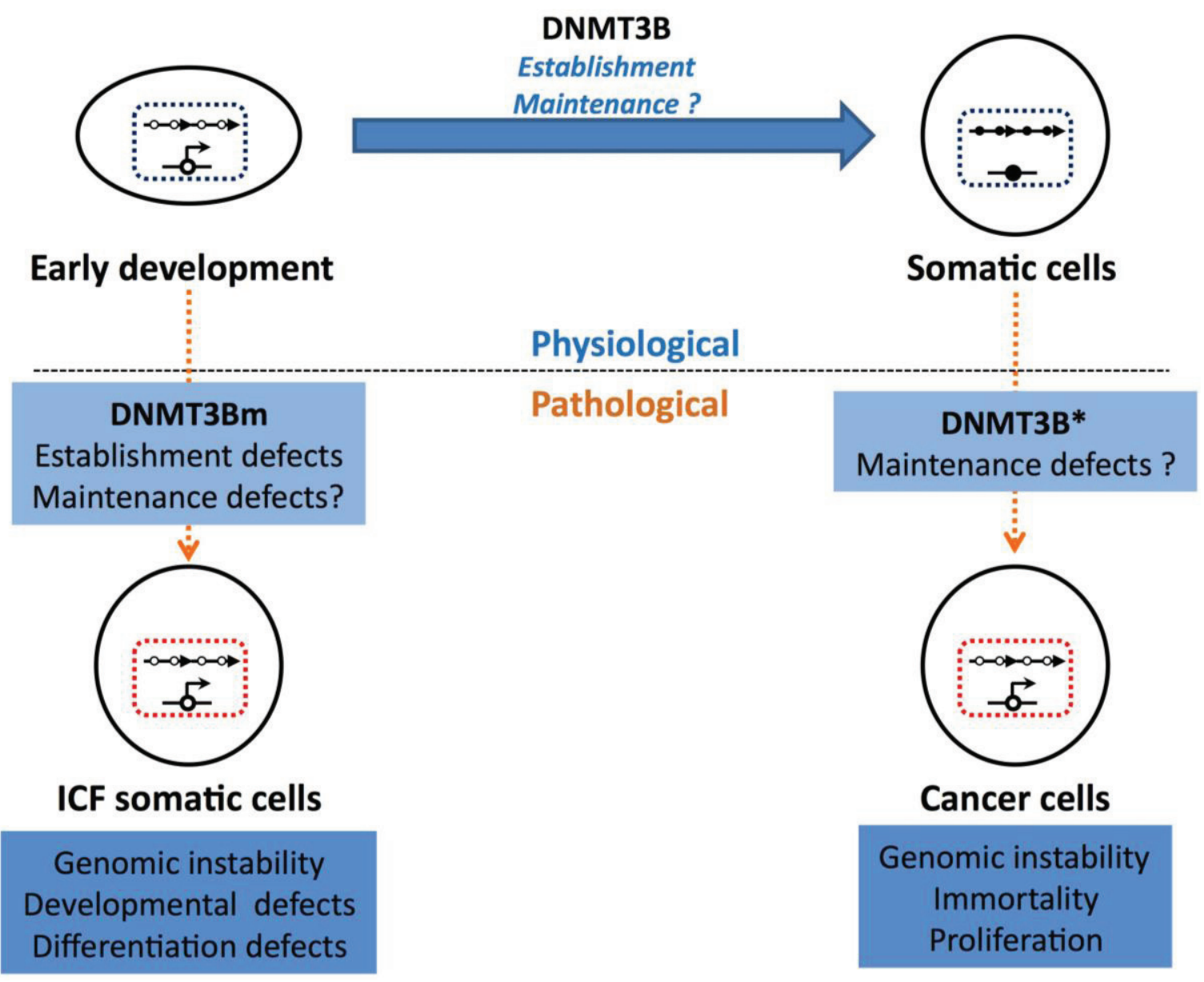

\subsection{Germ Line Genes and "Meiomitosis"}

The hypomethylation and off context expression of germ line genes in somatic cells during carcinogenesis is thought to confer phenotypic traits, including immortality, invasiveness, and immune evasion that are essential for the survival and function of gametes but are hijacked in somatic cells to drive malignancy [134]. In particular, postnatal spermatogenesis is characterized by drastic chromatin rearrangements during meiotic recombination; genome-wide histone hyperacetylation is followed by the replacement of histones with basic proteins called protamines, which leads to the extreme compaction of the genome in mature sperm. Thus, the ectopic activation of this program in 
somatic cells may create a favorable environment for the alteration of the genome and/or the epigenome [135]. Furthermore, the ectopic expression of germ line (and placental) genes is predictive of poor prognosis irrespective of tumor size, metastasis stage, or histological subtype in human lung cancers [136]. The coexistence of meiotic proteins and mitotic-specific proteins in cancer cells may lead to abnormal chromosome segregation and aneuploidy, a hallmark of human cancer and a driver of genomic instability [137]. Although this has not been formally tested, the ectopic expression of germ line genes drives the growth of malignant brain tumors in Drosophila melanogaster [138]. In ICF syndrome, the finding that particular germ line genes are also aberrantly expressed in ICF1 patients suggests that they may participate in chromosomal instability in this syndrome. However, the finding that they are not expressed in ICF2 patients [130], raises the possibility that this illicit activation may not only contribute to the pathogenesis of ICF but also to the diversification of ICF phenotypes. This link, however, as well as the potential mechanism underlying it, remains to be established.

\subsection{Transcription of Satellite Repeats and Chromosomal Instability}

During early development in the mouse, satellite sequences are transcribed in the testis and brain [139], in undifferentiated ESCs [140], and in pre-implantation embryos [48]. However, in most adult tissues pericentromeric and centromeric regions are not transcribed, or at low levels. In this context, the transcription of these regions appears to be spatially and temporally regulated throughout cell cycle $[47,141]$, and transcripts that arise from them participate in the establishment of pericentromeric heterochromatin domains and centromere-associated complexes [47,48].

How perturbations to the methylation status of these regions directly affect cellular phenotypes is not known. In addition to the alteration of gene expression programs, the hypomethylation of satellite repeats is believed to contribute to chromosomal instability that is typical of cancer cells and ICF patient cells. An emerging possibility is that hypomethylation leads to the aberrant transcription of underlying repeat sequences, as illustrated by treatment of cultured cells with the DNA demethylating agent 5'azacytidine that promotes the accumulation of pericentromeric transcripts in human cells [142] or centromeric transcripts in mouse cells [46]. In support of this hypothesis, the aberrant accumulation of pericentromeric transcripts has been detected in cancer cell lines [142] and in primary human epithelial cancers [143], as well as in lymphoblastoid cells from an ICF patient [144], consistent with B-lymphocytes being particularly affected in these patients. Likewise, in senescent embryonic lung fibroblasts and epithelial carcinoma cells, hypomethylation and decondensation of the 1q12 locus is associated with a high abundance of pericentromeric transcripts [145]. Although these examples do not give any clue as to the causal link between high levels of satellite transcripts and chromosomal instability, the forced accumulation of satellite transcripts leads to mitotic defects such as multiple spindle attachments, loss of sister chromatid cohesion and aneuploidy [46,146,147]. Yet, the absence of strong constitutive transcription of satellite repeats in most human or murine ICF cells suggests that hypomethylation per se is not sufficient to promote their transcription, at least in cultured cells. Overall, there is a clear correlation between DNA hypomethylation of satellite repeats and their strong transcription in certain cellular contexts, although the relationship between methylation and transcription at these regions appears complex. However, this raises the interesting possibility that 
tissue-specific or developmental stage-specific factors are required, and may explain why all tissues of the ICF patients or mice are not similarly affected.

It is also possible that DNA methylation at centromeric repeats plays additional roles besides transcriptional regulation. The number of centromeric repeats in mouse Dnmt $3 a^{-/-}$Dnmt $3 b^{-/-}$ES cells is lower than in wild-type ES cells, and this is associated with a higher rate of centromere mitotic recombination in Dnmt3a $a^{-/-}$Dnmt $3 b^{-/-}$ES cells [148]. Thus, DNA methylation may be an important mechanism to suppress illicit centromeric mitotic recombination.

The hypomethylation of telomeric and sub-telomeric repeats in ICF patient cells is also associated with abnormally short telomeres in both the telomerase-positive and -negative cells, suggesting that DNA methylation may protect cells from telomere shortening [58]. Furthermore, ICF cells express abnormally high levels of telomeric repeat containing RNA (TERRA), suggesting that methylation is important for keeping transcription of these regions at low levels and that elevated levels of TERRA cause telomere shortening by unknown mechanisms [58].

\subsection{Hypomethylation of Satellite Repeats and Perturbed Nuclear Organization}

Repetitive sequences play an essential role in the three-dimensional organization of the nucleus through the formation of repressive compartments $[149,150]$. Thus, perturbations to heterochromatin regions, known to have long-range influences on gene regulation through position effects, in cancer or ICF cells, probably have profound effects on gene expression. As discussed above, the transcriptional activation of heterochromatin regions in this context is likely to play an important role in these perturbations (Figure 3).

Alterations to juxtacentromeric heterochromatin resulting from DNA hypomethylation leads to perturbed nuclear heterochromatin and mis-localization of associated proteins [151]. These perturbations may affect gene expression in trans and contribute to the developmental defects of ICF patients and to the phenotypic characteristics of cancer cells. The nuclear volume occupied by the juxtacentromeric compartments of chromosomes 1 and 16, along with their positioning relative to the nuclear periphery, differs between cells from ICF patients and those from healthy individuals [152]. The authors of this study confirmed perturbed expression of four genes located on chromosome 1 that were previously identified as deregulated in ICF patient cells [153]. Three of these genes had CpG islands in their predicted regulatory regions but showed no perturbation to promoter methylation. Instead, upregulated genes were more often positioned away from juxtacentromeric heterochromatin of chromosome 1 in ICF patient cells than in control cells. Therefore, by affecting long-range gene-heterochromatin associations, the altered subnuclear organization of the hypomethylated satellite sequences interferes with heterochromatin mediated gene silencing and contributes to some of the changes in gene expression observed in ICF cells. 
Figure 3. The effect of high levels of satellite transcripts is context dependent. We represent here the example of murine chromosomes and murine cells for which the forced expression of centromeric transcripts leads to phenotypes that are reminiscent of perturbations described for cancer and ICF cells. DNA hypomethylation of centromeric DNA repeats is not sufficient to drive the transcription of these repeats but may define a molecular context that promotes activated transcription in particular cellular contexts. Transcription of these repeats is low in somatic cells whereas high levels have been described in embryonic stem cells (ESCs) and germ cells, although it is not clear whether this is required for their identity. In physiopathological contexts where the function of Dnmt $3 b$ is altered and centromeric repeats are hypomethylated, high levels of centromeric transcripts accumulate only in particular somatic tissues. Here, they may trigger molecular defects such as genomic instability and perturb nuclear heterochromatin domains implicated in the repression of gene expression, thus leading to perturbed cellular phenotypes. As a consequence, the abnormal accumulation of satellite transcripts may act as a master switch in diseases characterized by alterations to methylation status, like cancer and ICF syndrome.

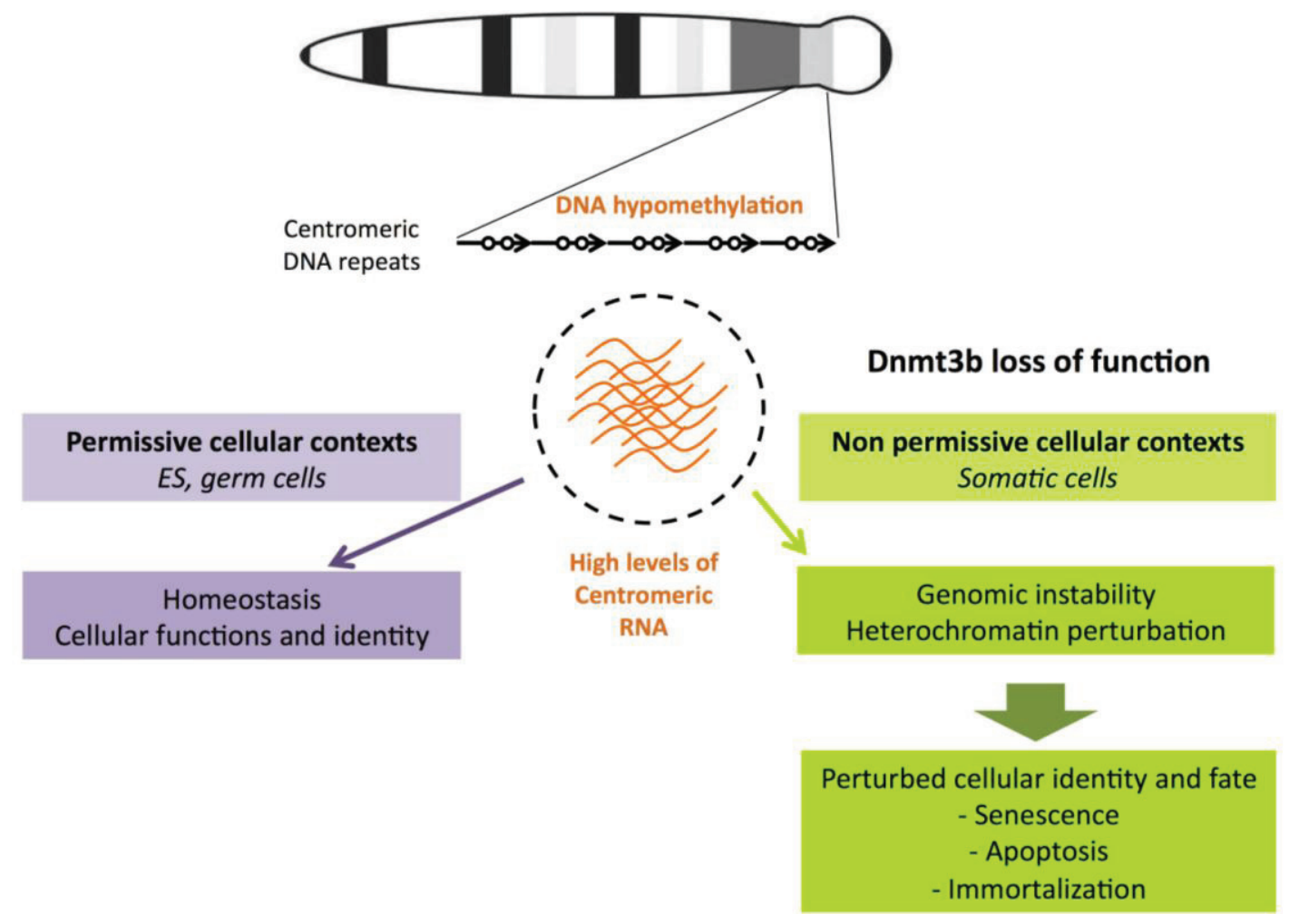

\section{Conclusions and Perspectives}

The establishment of correct patterns of DNA methylation is essential for normal development, and the loss of or deviation from these patterns is a critical event in many human diseases. Thus, the identification of the targets of de novo DNMTs is crucial for our understanding of normal and pathological development, and animal models have been indispensable for the elucidation of methylation patterning.

No clear mechanistic link between genomic hypomethylation and chromosomal instability has been yet established, and cells from ICF patients and ICF mouse models constitute powerful tools to study 
the complex relationship between DNA hypomethylation and pathological phenotypes, although there are some limitations regarding the sequence conservation between human and mouse centromeric/pericentromeric satellite repeats. They also provide a unique opportunity to study the targets and function of DNMT3B in a human or murine context free from experimental manipulation. Indeed, these systems may be used to examine the role of DNA methylation at satellite repeats, the complex relationship between hypomethylation and transcription of these regions, and the relevance for perturbed molecular and nuclear phenotypes. Many questions still remain about the identity of factors that are important for the establishment of DNA methylation at germ line genes and centromeric repeats and the study of the ICF syndrome is likely to provide some clues to this conundrum. Indeed, human genetic studies of the ICF syndrome have identified a new player in DNA methylation at DNA repeats in centromeric regions, ZBTB24, and functional studies will soon dissect the role of this factor in the establishment or maintenance of methylation. The identification of more factors from the study of ICFX patients seems probable and will contribute to our understanding of how DNA methylation is established and maintained at centromeric and pericentromeric DNA repeats. Finally, further studies of the significance of the off-context expression of DNMT3B targets, in particular centromeric RNA and germ line genes, will help to elucidate the specific contribution of these factors to pathological phenotypes and may even firmly establish them as viable therapeutic targets or powerful biomarkers.

\section{Acknowledgments}

We would like to thank Nathalie Beaujean, Alice Jouneau, Sara Selig and Claire Vourc'h for longstanding discussions on various issues that we discussed here. Work in CF's lab was supported by ANR (Agence Nationale pour la Recherche; ANR-09-GENO-035), Fondation Maladies Rares, Ligue Nationale Contre le Cancer and Gefluc-les entreprises contre le cancer. E.W. was supported by the French Ministry of Research and Ligue Nationale Contre le Cancer.

\section{Author Contributions}

Guillaume Velasco and Emma L. Walton drafted the manuscript. Claire Francastel supervised the writting and revised the manuscript.

\section{Conflicts of Interest}

The authors declare that they have no conflict of interest.

\section{References}

1. Jones, P.A.; Taylor, S.M.; Wilson, V. DNA modification, differentiation, and transformation. J. Exp. Zool. 1983, 228, 287-295.

2. Meissner, A.; Mikkelsen, T.S.; Gu, H.; Wernig, M.; Hanna, J.; Sivachenko, A.; Zhang, X.; Bernstein, B.E.; Nusbaum, C.; Jaffe, D.B.; et al. Genome-scale DNA methylation maps of pluripotent and differentiated cells. Nature 2010, 454, 766-770. 
3. Weber, M.; Hellmann, I.; Stadler, M.B.; Ramos, L.; Paabo, S.; Rebhan, M.; Schubeler, D. Distribution, silencing potential and evolutionary impact of promoter DNA methylation in the human genome. Nat. Genet. 2007, 39, 457-466.

4. Weber, M.; Schubeler, D. Genomic patterns of DNA methylation: Targets and function of an epigenetic mark. Curr. Opin. Cell Biol. 2007, 19, 273-280.

5. Illingworth, R.; Kerr, A.; Desousa, D.; Jorgensen, H.; Ellis, P.; Stalker, J.; Jackson, D.; Clee, C.; Plumb, R.; Rogers, J.; et al. A novel CpG island set identifies tissue-specific methylation at developmental gene loci. PLoS Biol. 2008, 6, e22.

6. Razin, A.; Cedar, H. DNA methylation and gene expression. Microbiol. Rev. 1991, 55, 451-458.

7. Bird, A.P.; Wolffe, A.P. Methylation-induced repression-Belts, braces, and chromatin. Cell 1999, 99, 451-454.

8. Shukla, S.; Kavak, E.; Gregory, M.; Imashimizu, M.; Shutinoski, B.; Kashlev, M.; Oberdoerffer, P.; Sandberg, R.; Oberdoerffer, S. CTCF-promoted RNA polymerase II pausing links DNA methylation to splicing. Nature 2011, 479, 74-79.

9. Maunakea, A.K.; Nagarajan, R.P.; Bilenky, M.; Ballinger, T.J.; D'Souza, C.; Fouse, S.D.; Johnson, B.E.; Hong, C.; Nielsen, C.; Zhao, Y.; et al. Conserved role of intragenic DNA methylation in regulating alternative promoters. Nature 2010, 466, 253-257.

10. Li, E.; Bestor, T.H.; Jaenisch, R. Targeted mutation of the DNA methyltransferase gene results in embryonic lethality. Cell 1992, 69, 915-926.

11. Walsh, C.P.; Chaillet, J.R.; Bestor, T.H. Transcription of IAP endogenous retroviruses is constrained by cytosine methylation. Nat. Genet. 1998, 20, 116-117.

12. Sasaki, H.; Jones, P.A.; Chaillet, J.R.; Ferguson-Smith, A.C.; Barton, S.C.; Reik, W.; Surani, M.A. Parental imprinting: Potentially active chromatin of the repressed maternal allele of the mouse insulin-like growth factor II (IGF2) gene. Genes Dev. 1992, 6, 1843-1856.

13. Li, E.; Beard, C.; Jaenisch, R. Role for DNA methylation in genomic imprinting. Nature 1993, 366, 362-365.

14. Panning, B.; Jaenisch, R. DNA hypomethylation can activate Xist expression and silence X-linked genes. Genes Dev. 1996, 10, 1991-2002.

15. Okano, M.; Xie, S.; Li, E. Cloning and characterization of a family of novel mammalian DNA (cytosine-5) methyltransferases. Nat. Genet. 1998, 19, 219-220.

16. Bostick, M.; Kim, J.K.; Esteve, P.O.; Clark, A.; Pradhan, S.; Jacobsen, S.E. Uhrf1 plays a role in maintaining DNA methylation in mammalian cells. Science 2007, 317, 1760-1764.

17. Hermann, A.; Goyal, R.; Jeltsch, A. The Dnmt1 DNA-(cytosine-C5)-methyltransferase methylates DNA processively with high preference for hemimethylated target sites. J. Biol. Chem. 2004, 279, 48350-48359.

18. Chedin, F.; Lieber, M.R.; Hsieh, C.L. The DNA methyltransferase-like protein DNMT3L stimulates de novo methylation by Dnmt3a. Proc. Natl. Acad. Sci. USA 2002, 99, 16916-16921.

19. Guenatri, M.; Duffie, R.; Iranzo, J.; Fauque, P.; Bourc'his, D. Plasticity in Dnmt3L-dependent and -independent modes of de novo methylation in the developing mouse embryo. Development 2013, 140, 562-572.

20. Okano, M.; Bell, D.W.; Haber, D.A.; Li, E. DNA methyltransferases Dnmt3a and Dnmt3b are essential for de novo methylation and mammalian development. Cell 1999, 99, 247-257. 
21. Liang, G.; Chan, M.F.; Tomigahara, Y.; Tsai, Y.C.; Gonzales, F.A.; Li, E.; Laird, P.W.; Jones, P.A. Cooperativity between DNA methyltransferases in the maintenance methylation of repetitive elements. Mol. Cell Biol. 2002, 22, 480-491.

22. Chen, T.; Ueda, Y.; Dodge, J.E.; Wang, Z.; Li, E. Establishment and maintenance of genomic methylation patterns in mouse embryonic stem cells by Dnmt3a and Dnmt3b. Mol. Cell. Biol. 2003, 23, 5594-5605.

23. Walton, E.L.; Francastel, C.; Velasco, G. Maintenance of DNA methylation: Dnmt3b joins the dance. Epigenetics 2011, 6, 1373-1377.

24. Chen, T.; Tsujimoto, N.; Li, E. The PWWP domain of Dnmt3a and Dnmt3b is required for directing DNA methylation to the major satellite repeats at pericentric heterochromatin. Mol. Cell Biol. 2004, 24, 9048-9058.

25. Bachman, K.E.; Rountree, M.R.; Baylin, S.B. Dnmt3a and Dnmt3b are transcriptional repressors that exhibit unique localization properties to heterochromatin. J. Biol. Chem. 2001, 276, 32282-32287.

26. Zhang, Y.; Jurkowska, R.; Soeroes, S.; Rajavelu, A.; Dhayalan, A.; Bock, I.; Rathert, P.; Brandt, O.; Reinhardt, R.; Fischle, W.; et al. Chromatin methylation activity of Dnmt3a and Dnmt3a/3L is guided by interaction of the add domain with the histone H3 tail. Nucl. Acids Res. 2010, 38, 4246-4253.

27. Gordon, C.A.; Hartono, S.R.; Chedin, F. Inactive DNMT3B splice variants modulate de novo DNA methylation. PLoS One 2013, 8, e69486.

28. Gopalakrishnan, S.; van Emburgh, B.O.; Shan, J.; Su, Z.; Fields, C.R.; Vieweg, J.; Hamazaki, T.; Schwartz, P.H.; Terada, N.; Robertson, K.D. A novel DNMT3B splice variant expressed in tumor and pluripotent cells modulates genomic DNA methylation patterns and displays altered DNA binding. Mol. Cancer Res. 2009, 7, 1622-1634.

29. Ostler, K.R.; Davis, E.M.; Payne, S.L.; Gosalia, B.B.; Exposito-Cespedes, J.; le Beau, M.M.; Godley, L.A. Cancer cells express aberrant DNMT3B transcripts encoding truncated proteins. Oncogene 2007, 26, 5553-5563.

30. Saito, Y.; Kanai, Y.; Sakamoto, M.; Saito, H.; Ishii, H.; Hirohashi, S. Overexpression of a splice variant of DNA methyltransferase 3b, DNMT3B4, associated with DNA hypomethylation on pericentromeric satellite regions during human hepatocarcinogenesis. Proc. Natl. Acad. Sci. USA 2002, 99, 10060-10065.

31. Wang, L.; Wang, J.; Sun, S.; Rodriguez, M.; Yue, P.; Jang, S.J.; Mao, L. A novel DNMT3B subfamily, deltaDNMT3B, is the predominant form of DNMT3B in non-small cell lung cancer. Int. J. Oncol. 2008, 29, 201-207.

32. Weisenberger, D.J.; Velicescu, M.; Cheng, J.C.; Gonzales, F.A.; Liang, G.; Jones, P.A. Role of the DNA methyltransferase variant Dnmt3b3 in DNA methylation. Mol. Cancer Res. 2004, 2, 62-72.

33. Weisenberger, D.J.; Velicescu, M.; Preciado-Lopez, M.A.; Gonzales, F.A.; Tsai, Y.C.; Liang, G.; Jones, P.A. Identification and characterization of alternatively spliced variants of DNA methyltransferase 3a in mammalian cells. Gene 2002, 298, 91-99.

34. Huntriss, J.; Hinkins, M.; Oliver, B.; Harris, S.E.; Beazley, J.C.; Rutherford, A.J.; Gosden, R.G.; Lanzendorf, S.E.; Picton, H.M. Expression of mRNAs for DNA methyltransferases and 
methyl-CpG-binding proteins in the human female germ line, preimplantation embryos, and embryonic stem cells. Mol. Reprod. Dev. 2004, 67, 323-336.

35. Robertson, K.D.; Uzvolgyi, E.; Liang, G.; Talmadge, C.; Sumegi, J.; Gonzales, F.A.; Jones, P.A. The human DNA methyltransferases (DNMTs) 1, 3a and 3b: Coordinate mRNA expression in normal tissues and overexpression in tumors. Nucl. Acids Res. 1999, 27, 2291-2298.

36. Xu, G.L.; Bestor, T.H.; Bourc'his, D.; Hsieh, C.L.; Tommerup, N.; Bugge, M.; Hulten, M.; Qu, X.; Russo, J.J.; Viegas-Pequignot, E. Chromosome instability and immunodeficiency syndrome caused by mutations in a DNA methyltransferase gene. Nature 1999, 402, 187-191.

37. Guenatri, M.; Bailly, D.; Maison, C.; Almouzni, G. Mouse centric and pericentric satellite repeats form distinct functional heterochromatin. J. Cell. Biol. 2004, 166, 493-505.

38. Yamagishi, Y.; Sakuno, T.; Shimura, M.; Watanabe, Y. Heterochromatin links to centromeric protection by recruiting shugoshin. Nature 2008, 455, 251-255.

39. Choo, K.H. The Centromere; Oxford University Press Inc.: New York, NY, USA, 1997.

40. Martens, J.H.; O’Sullivan, R.J.; Braunschweig, U.; Opravil, S.; Radolf, M.; Steinlein, P.; Jenuwein, T. The profile of repeat-associated histone lysine methylation states in the mouse epigenome. EMBO J. 2005, 24, 800-812.

41. Vourc'h, C.; Biamonti, G. Transcription of satellite DNAs in mammals. Prog. Mol. Subcell. Biol. 2011, 51, 95-118.

42. Choo, K.H. Domain organization at the centromere and neocentromere. Dev. Cell. 2001, 1, 165-177.

43. Earnshaw, W.C.; Cooke, C.A. Proteins of the inner and outer centromere of mitotic chromosomes. Genome 1989, 31, 541-552.

44. Eymery, A.; Callanan, M.; Vourc'h, C. The secret message of heterochromatin: New insights into the mechanisms and function of centromeric and pericentric repeat sequence transcription. Int. J. Dev. Biol. 2009, 53, 259-268.

45. Hall, L.E.; Mitchell, S.E.; O’Neill, R.J. Pericentric and centromeric transcription: A perfect balance required. Chromosom. Res. 2012, 20, 535-546.

46. Bouzinba-Segard, H.; Guais, A.; Francastel, C. Accumulation of small murine minor satellite transcripts leads to impaired centromeric architecture and function. Proc. Natl. Acad. Sci. USA 2006, 103, 8709-8714.

47. Ferri, F.; Bouzinba-Segard, H.; Velasco, G.; Hubé, F.; Francastel, C. Non-coding murine centromeric transcripts associate with and potentiate Aurora B kinase. Nucl. Acids Res. 2009, 37, 5071-5080.

48. Probst, A.V.; Okamoto, I.; Casanova, M.; El Marjou, F.; Le Baccon, P.; Almouzni, G. A strand-specific burst in transcription of pericentric satellites is required for chromocenter formation and early mouse development. Dev. Cell. 2010, 19, 625-638.

49. Borgel, J.; Guibert, S.; Li, Y.; Chiba, H.; Schubeler, D.; Sasaki, H.; Forne, T.; Weber, M. Targets and dynamics of promoter DNA methylation during early mouse development. Nat. Genet. 2010, 42, 1093-1100.

50. Velasco, G.; Hube, F.; Rollin, J.; Neuillet, D.; Philippe, C.; Bouzinba-Segard, H.; Galvani, A.; Viegas-Pequignot, E.; Francastel, C. Dnmt3b recruitment through E2F6 transcriptional repressor 
mediates germ-line gene silencing in murine somatic tissues. Proc. Natl. Acad. Sci. USA 2010, 107, 9281-9286.

51. De Smet, C.; Lurquin, C.; Lethe, B.; Martelange, V.; Boon, T. DNA methylation is the primary silencing mechanism for a set of germ line- and tumor-specific genes with a CpG-rich promoter. Mol. Cell. Biol. 1999, 19, 7327-7335.

52. Maatouk, D.M.; Kellam, L.D.; Mann, M.R.; Lei, H.; Li, E.; Bartolomei, M.S.; Resnick, J.L. DNA methylation is a primary mechanism for silencing postmigratory primordial germ cell genes in both germ cell and somatic cell lineages. Development 2006, 133, 3411-3418.

53. Hackett, J.A.; Reddington, J.P.; Nestor, C.E.; Dunican, D.S.; Branco, M.R.; Reichmann, J.; Reik, W.; Surani, M.A.; Adams, I.R.; Meehan, R.R. Promoter DNA methylation couples genome-defence mechanisms to epigenetic reprogramming in the mouse germline. Development 2012, 139, 3623-3632.

54. Tsien, F.; Sun, B.; Hopkins, N.E.; Vedanarayanan, V.; Figlewicz, D.; Winokur, S.; Ehrlich, M. Methylation of the FSHD syndrome-linked subtelomeric repeat in normal and FSHD cell cultures and tissues. Mol. Genet. Metab. 2001, 74, 322-331.

55. Nishiyama, R.; Qi, L.; Tsumagari, K.; Weissbecker, K.; Dubeau, L.; Champagne, M.; Sikka, S.; Nagai, H.; Ehrlich, M. A DNA repeat, NBL2, is hypermethylated in some cancers but hypomethylated in others. Cancer Biol. Ther. 2005, 4, 440-448.

56. Kondo, T.; Bobek, M.P.; Kuick, R.; Lamb, B.; Zhu, X.; Narayan, A.; Bourc'his, D.; Viegas-Pequignot, E.; Ehrlich, M.; Hanash, S.M. Whole-genome methylation scan in ICF syndrome: Hypomethylation of non-satellite DNA repeats D4Z4 and NBL2. Hum. Mol. Genet. 2000, 9, 597-604.

57. Miniou, P.; Bourc'his, D.; Molina Gomes, D.; Jeanpierre, M.; Viegas-Pequignot, E. Undermethylation of Alu sequences in ICF syndrome: Molecular and in situ analysis. Cytogenet. Cell. Genet. 1997, 77, 308-313.

58. Yehezkel, S.; Segev, Y.; Viegas-Pequignot, E.; Skorecki, K.; Selig, S. Hypomethylation of subtelomeric regions in ICF syndrome is associated with abnormally short telomeres and enhanced transcription from telomeric regions. Hum. Mol. Genet. 2008, 17, 2776-2789.

59. Brock, G.J.; Charlton, J.; Bird, A. Densely methylated sequences that are preferentially localized at telomere-proximal regions of human chromosomes. Gene 1999, 240, 269-277.

60. Craig, J.M.; Earle, E.; Canham, P.; Wong, L.H.; Anderson, M.; Choo, K.H. Analysis of mammalian proteins involved in chromatin modification reveals new metaphase centromeric proteins and distinct chromosomal distribution patterns. Hum. Mol. Genet. 2003, 12, 3109-3121.

61. Ueda, Y.; Okano, M.; Williams, C.; Chen, T.; Georgopoulos, K.; Li, E. Roles for Dnmt3b in mammalian development: A mouse model for the ICF syndrome. Development 2006, 133, $1183-1192$.

62. Marks, H.; Kalkan, T.; Menafra, R.; Denissov, S.; Jones, K.; Hofemeister, H.; Nichols, J.; Kranz, A.; Stewart, A.F.; Smith, A.; et al. The transcriptional and epigenomic foundations of ground state pluripotency. Cell. 2012, 149, 590-604.

63. Kriaucionis, S.; Heintz, N. The nuclear DNA base 5-hydroxymethylcytosine is present in purkinje neurons and the brain. Science 2009, 324, 929-930. 
64. Tahiliani, M.; Koh, K.P.; Shen, Y.; Pastor, W.A.; Bandukwala, H.; Brudno, Y.; Agarwal, S.; Iyer, L.M.; Liu, D.R.; Aravind, L.; et al. Conversion of 5-methylcytosine to 5-hydroxymethylcytosine in mammalian DNA by MLL partner TET1. Science 2009, 324, 930-935.

65. Seisenberger, S.; Peat, J.R.; Hore, T.A.; Santos, F.; Dean, W.; Reik, W. Reprogramming DNA methylation in the mammalian life cycle: Building and breaking epigenetic barriers. Philos. Trans. R Soc. Lond. B Biol. Sci. 2013, 368, 20110330.

66. Guibert, S.; Weber, M. Functions of DNA methylation and hydroxymethylation in mammalian development. Curr. Top. Dev. Biol. 2013, 104, 47-83.

67. Sakaue, M.; Ohta, H.; Kumaki, Y.; Oda, M.; Sakaide, Y.; Matsuoka, C.; Yamagiwa, A.; Niwa, H.; Wakayama, T.; Okano, M. DNA methylation is dispensable for the growth and survival of the extraembryonic lineages. Curr. Biol. 2010, 20, 1452-1457.

68. Tsumura, A.; Hayakawa, T.; Kumaki, Y.; Takebayashi, S.; Sakaue, M.; Matsuoka, C.; Shimotohno, K.; Ishikawa, F.; Li, E.; Ueda, H.R.; et al. Maintenance of self-renewal ability of mouse embryonic stem cells in the absence of DNA methyltransferases Dnmt1, Dnmt3a and Dnmt3b. Genes Cells 2006, 11, 805-814.

69. Jackson-Grusby, L.; Beard, C.; Possemato, R.; Tudor, M.; Fambrough, D.; Csankovszki, G.; Dausman, J.; Lee, P.; Wilson, C.; Lander, E.; et al. Loss of genomic methylation causes p53-dependent apoptosis and epigenetic deregulation. Nat. Genet. 2001, 27, 31-39.

70. Senner, C.E.; Krueger, F.; Oxley, D.; Andrews, S.; Hemberger, M. DNA methylation profiles define stem cell identity and reveal a tight embryonic-extraembryonic lineage boundary. Stem Cells 2012, 30, 2732-2745.

71. Veillard, A.C.; Marks, H.; Bernardo, A.S.; Jouneau, L.; Laloe, D.; Boulanger, L.; Kaan, A.; Brochard, V.; Tosolini, M.; Pedersen, R.; et al. Stable methylation at promoters distinguishes epiblast stem cells from embryonic stem cells and the in vivo epiblast. Stem Cells Dev. 2014, 23, 2014-2029.

72. Habibi, E.; Brinkman, A.B.; Arand, J.; Kroeze, L.I.; Kerstens, H.H.; Matarese, F.; Lepikhov, K.; Gut, M.; Brun-Heath, I.; Hubner, N.C.; et al. Whole-genome bisulfite sequencing of two distinct interconvertible DNA methylomes of mouse embryonic stem cells. Cell. Stem Cell. 2013, 13, $360-369$.

73. Leitch, H.G.; McEwen, K.R.; Turp, A.; Encheva, V.; Carroll, T.; Grabole, N.; Mansfield, W.; Nashun, B.; Knezovich, J.G.; Smith, A.; et al. Naive pluripotency is associated with global DNA hypomethylation. Nat. Struct. Mol. Biol. 2013, 20, 311-316.

74. Arand, J.; Spieler, D.; Karius, T.; Branco, M.R.; Meilinger, D.; Meissner, A.; Jenuwein, T.; $\mathrm{Xu}, \mathrm{G}$.; Leonhardt, H.; Wolf, V.; et al. In vivo control of CpG and non- CpG DNA methylation by DNA methyltransferases. PLoS Genet 2012, 8, e1002750.

75. Zvetkova, I.; Apedaile, A.; Ramsahoye, B.; Mermoud, J.E.; Crompton, L.A.; John, R.; Feil, R.; Brockdorff, N. Global hypomethylation of the genome in XX embryonic stem cells. Nat. Genet. 2005, 37, 1274-1279.

76. Grabole, N.; Tischler, J.; Hackett, J.A.; Kim, S.; Tang, F.; Leitch, H.G.; Magnusdottir, E.; Surani, M.A. Prdm14 promotes germline fate and naive pluripotency by repressing FGF signalling and DNA methylation. EMBO Rep. 2013, 14, 629-637. 
77. Guibert, S.; Forne, T.; Weber, M. Global profiling of DNA methylation erasure in mouse primordial germ cells. Genome Res. 2012, 22, 633-641.

78. Hajkova, P.; Erhardt, S.; Lane, N.; Haaf, T.; El-Maarri, O.; Reik, W.; Walter, J.; Surani, M.A. Epigenetic reprogramming in mouse primordial germ cells. Mech. Dev. 2002, 117, 15-23.

79. Lees-Murdock, D.J.; de Felici, M.; Walsh, C.P. Methylation dynamics of repetitive DNA elements in the mouse germ cell lineage. Genomics 2003, 82, 230-237.

80. La Salle, S.; Mertineit, C.; Taketo, T.; Moens, P.B.; Bestor, T.H.; Trasler, J.M. Windows for sex-specific methylation marked by DNA methyltransferase expression profiles in mouse germ cells. Dev. Biol. 2004, 268, 403-415.

81. Yamagata, K.; Yamazaki, T.; Miki, H.; Ogonuki, N.; Inoue, K.; Ogura, A.; Baba, T. Centromeric DNA hypomethylation as an epigenetic signature discriminates between germ and somatic cell lineages. Dev. Biol. 2007, 312, 419-426.

82. Riggs, A.D.; Xiong, Z. Methylation and epigenetic fidelity. Proc. Natl. Acad. Sci. USA 2004, 101, 4-5.

83. Brandeis, M.; Frank, D.; Keshet, I.; SIegfried, Z.; Mendelsohn, M.; Nemes, A.; Temper, V.; Razin, A.; Cedar, H. Sp1 elements protect a CpG island from de novo methylation. Nature 1994, 371, 435-438.

84. Macleod, D.; Charlton, J.; Cullins, J.; Bird, A.P. Sp1 sites in the mouse Aprt gene promoter are required to prevent methylation of the $\mathrm{CpG}$ island. Genes Dev. 1994, 8, 2282-2292.

85. Lienert, F.; Wirbelauer, C.; Som, I.; Dean, A.; Mohn, F.; Schubeler, D. Identification of genetic elements that autonomously determine DNA methylation states. Nat. Genet. 2011, 43, 1091-1097.

86. Wienholz, B.L.; Kareta, M.S.; Moarefi, A.H.; Gordon, C.A.; Ginno, P.A.; Chedin, F. Dnmt3L modulates significant and distinct flanking sequence preference for DNA methylation by Dnmt3a and Dnmt3b in vivo. PLoS Genet. 2010, 6, 1001106.

87. Hervouet, E.; Vallette, F.M.; Cartron, P.F. Dnmt3/transcription factor interactions as crucial players in targeted DNA methylation. Epigenetics 2009, 4, 487-499.

88. Maeda, I.; Okamura, D.; Tokitake, Y.; Ikeda, M.; Kawaguchi, H.; Mise, N.; Abe, K.; Noce, T.; Okuda, A.; Matsui, Y. Max is a repressor of germ cell-related gene expression in mouse embryonic stem cells. Nat. Commun. 2013, 4, 1754.

89. Gopalakrishnan, S.; Sullivan, B.A.; Trazzi, S.; Della Valle, G.; Robertson, K.D. DNMT3B interacts with constitutive centromere protein CENP-C to modulate DNA methylation and the histone code at centromeric regions. Hum. Mol. Genet. 2009, 18, 3178-3193.

90. Dennis, K.; Fan, T.; Geiman, T.; Yan, Q.; Muegge, K. Lsh, a member of the SNF2 family, is required for genome-wide methylation. Genes Dev. 2001, 15, 2940-2944.

91. Geiman, T.M.; Tessarollo, L.; Anver, M.R.; Kopp, J.B.; Ward, J.M.; Muegge, K. Lsh, a SNF2 family member, is required for normal murine development. Biochim. Biophys. Acta 2001, 1526, 211-220.

92. Huang, J.; Fan, T.; Yan, Q.; Zhu, H.; Fox, S.; Issaq, H.J.; Best, L.; Gangi, L.; Munroe, D.; Muegge, K. Lsh, an epigenetic guardian of repetitive elements. Nucl. Acids Res. 2004, 32, 5019-5028. 
93. Myant, K.; Termanis, A.; Sundaram, A.Y.; Boe, T.; Li, C.; Merusi, C.; Burrage, J.; de Las Heras, J.I.; Stancheva, I. Lsh and G9a/GLP complex are required for developmentally programmed DNA methylation. Genome Res. 2011, 21, 83-94.

94. Tao, Y.; Xi, S.; Shan, J.; Maunakea, A.; Che, A.; Briones, V.; Lee, E.Y.; Geiman, T.; Huang, J.; Stephens, R.; et al. Lsh, chromatin remodeling family member, modulates genome-wide cytosine methylation patterns at nonrepeat sequences. Proc. Natl. Acad. Sci. USA 2011, 108, 5626-5631.

95. Xi, S.; Geiman, T.M.; Briones, V.; Guang Tao, Y.; Xu, H.; Muegge, K. Lsh participates in DNA methylation and silencing of stem cell genes. Stem Cells 2009, 27, 2691-2702.

96. Dunican, D.S.; Cruickshanks, H.A.; Suzuki, M.; Semple, C.A.; Davey, T.; Arceci, R.J.; Greally, J.; Adams, I.R.; Meehan, R.R. Lsh regulates LTR retrotransposon repression independently of Dnmt3b function. Genome Biol. 2013, 14, R146.

97. Myant, K.; Stancheva, I. Lsh cooperates with DNA methyltransferases to repress transcription. Mol. Cell. Biol. 2008, 28, 215-226.

98. Aravin, A.A.; Sachidanandam, R.; Girard, A.; Fejes-Toth, K.; Hannon, G.J. Developmentally regulated piRNA clusters implicate MILI in transposon control. Science 2007, 316, 744-747.

99. Schmitz, K.M.; Mayer, C.; Postepska, A.; Grummt, I. Interaction of noncoding RNA with the rDNA promoter mediates recruitment of Dnmt3b and silencing of rRNA genes. Genes Dev. 2010, 24, 2264-2269.

100. Volpe, T.A.; Kidner, C.; Hall, I.M.; Teng, G.; Grewal, S.I.; Martienssen, R.A. Regulation of heterochromatic silencing and histone h3 lysine-9 methylation by RNAi. Science 2002, 297, 1833-1837.

101. Scarano, M.I.; Strazzullo, M.; Matarazzo, M.R.; D’Esposito, M. DNA methylation 40 years later: Its role in human health and disease. J. Cell. Physiol. 2005, 204, 21-35.

102. Wilson, A.S.; Power, B.E.; Molloy, P.L. DNA hypomethylation and human diseases. Biochim. Biophys. Acta. 2007, 1775, 138-162.

103. Robertson, K.D. DNA methylation and human disease. Nat. Rev. Genet. 2005, 6, 597-610.

104. Gronbaek, K.; Hother, C.; Jones, P.A. Epigenetic changes in cancer. APMIS 2007, 115, 1039-1059.

105. Feinberg, A.P.; Vogelstein, B. Hypomethylation distinguishes genes of some human cancers from their normal counterparts. Nature 1983, 301, 89-92.

106. Ehrlich, M. DNA hypomethylation in cancer cells. Epigenomics 2009, 1, 239-259.

107. Feinberg, A.P.; Vogelstein, B. Hypomethylation of Ras oncogenes in primary human cancers. Biochem. Biophys. Res. Commun. 1983, 111, 47-54.

108. Scanlan, M.J.; Gure, A.O.; Jungbluth, A.A.; Old, L.J.; Chen, Y.T. Cancer/testis antigens: An expanding family of targets for cancer immunotherapy. Immunol. Rev. 2002, 188, 22-32.

109. Sincic, N.; Herceg, Z. DNA methylation and cancer: Ghosts and angels above the genes. Curr. Opin. Oncol. 2011, 23, 69-76.

110. Vasanthakumar, A.; Lepore, J.B.; Zegarek, M.H.; Kocherginsky, M.; Singh, M.; Davis, E.M.; Link, P.A.; Anastasi, J.; Le Beau, M.M.; Karpf, A.R.; et al. Dnmt3b is a haploinsufficient tumor suppressor gene in myc-induced lymphomagenesis. Blood 2013, 121, 2059-2063.

111. Van Emburgh, B.O.; Robertson, K.D. Modulation of Dnmt3b function in vitro by interactions with Dnmt31, Dnmt3a and Dnmt3b splice variants. Nucl. Acids Res. 2011, 39, 4984-5002. 
112. Almeida, L.G.; Sakabe, N.J.; de Oliveira, A.R.; Silva, M.C.; Mundstein, A.S.; Cohen, T.; Chen, Y.T.; Chua, R.; Gurung, S.; Gnjatic, S.; et al. CTdatabase: a knowledge-base of high-throughput and curated data on cancer-testis antigens. Nucl. Acids Res. 2009, 37, D816-D819.

113. Hansen, R.S.; Wijmenga, C.; Luo, P.; Stanek, A.M.; Canfield, T.K.; Weemaes, C.M.; Gartler, S.M. The Dnmt3b DNA methyltransferase gene is mutated in the ICF immunodeficiency syndrome. Proc. Natl. Acad. Sci. USA 1999, 96, 14412-14417.

114. Fryns, J.P.; Azou, M.; Jaeken, J.; Eggermont, E.; Pedersen, J.C.; van den Berghe, H. Centromeric instability of chromosomes 1, 9, and 16 associated with combined immunodeficiency. Hum. Genet. 1981, 57, 108-110.

115. Tiepolo, L.; Maraschio, P.; Gimelli, G.; Cuoco, C.; Gargani, G.F.; Romano, C. Multibranched chromosomes 1, 9, and 16 in a patient with combined $\operatorname{IgA}$ and $\operatorname{IgE}$ deficiency. Hum. Genet. 1979, 51, 127-137.

116. Ehrlich, M.; Buchanan, K.L.; Tsien, F.; Jiang, G.; Sun, B.; Uicker, W.; Weemaes, C.M.; Smeets, D.; Sperling, K.; Belohradsky, B.H.; et al. DNA methyltransferase 3B mutations linked to the ICF syndrome cause dysregulation of lymphogenesis genes. Hum. Mol. Genet. 2001, 10, 2917-2931.

117. Hagleitner, M.M.; Lankester, A.; Maraschio, P.; Hulten, M.; Fryns, J.P.; Schuetz, C.; Gimelli, G.; Davies, E.G.; Gennery, A.; Belohradsky, B.H.; et al. Clinical spectrum of immunodeficiency, centromeric instability and facial dysmorphism (icf syndrome). J. Med. Genet. 2008, 45, 93-99.

118. Carpenter, N.J.; Filipovich, A.; Blaese, R.M.; Carey, T.L.; Berkel, A.I. Variable immunodeficiency with abnormal condensation of the heterochromatin of chromosomes 1, 9, and 16. J. Pediatr. 1988, 112, 757-760.

119. Maraschio, P.; Zuffardi, O.; Dalla Fior, T.; Tiepolo, L. Immunodeficiency, centromeric heterochromatin instability of chromosomes 1, 9, and 16, and facial anomalies: The ICF syndrome. J. Med. Genet. 1988, 25, 173-180.

120. Tuck-Muller, C.M.; Narayan, A.; Tsien, F.; Smeets, D.F.; Sawyer, J.; Fiala, E.S.; Sohn, O.S.; Ehrlich, M. DNA hypomethylation and unusual chromosome instability in cell lines from ICF syndrome patients. Cytogenet. Cell. Genet. 2000, 89, 121-128.

121. Jeanpierre, M.; Turleau, C.; Aurias, A.; Prieur, M.; Ledeist, F.; Fischer, A.; Viegas-Pequignot, E. An embryonic-like methylation pattern of classical satellite DNA is observed in ICF syndrome. Hum. Mol. Genet. 1993, 2, 731-735.

122. Ji, W.; Hernandez, R.; Zhang, X.Y.; Qu, G.Z.; Frady, A.; Varela, M.; Ehrlich, M. DNA demethylation and pericentromeric rearrangements of chromosome 1. Mutat. Res. 1997, 379, 33-41.

123. Jiang, Y.L.; Rigolet, M.; Bourc'his, D.; Nigon, F.; Bokesoy, I.; Fryns, J.P.; Hulten, M.; Jonveaux, P.; Maraschio, P.; Megarbane, A.; et al. Dnmt3b mutations and DNA methylation defect define two types of ICF syndrome. Hum. Mutat. 2005, 25, 56-63.

124. Wijmenga, C.; Hansen, R.S.; Gimelli, G.; Bjorck, E.J.; Davies, E.G.; Valentine, D.; Belohradsky, B.H.; van Dongen, J.J.; Smeets, D.F.; van den Heuvel, L.P.; et al. Genetic variation in ICF syndrome: Evidence for genetic heterogeneity. Hum. Mutat. 2000, 16, 509-517.

125. Gowher, H.; Jeltsch, A. Molecular enzymology of the catalytic domains of the Dnmt3a and Dnmt3b DNA methyltransferases. J. Biol. Chem. 2002, 277, 20409-20414. 
126. Moarefi, A.H.; Chedin, F. ICF syndrome mutations cause a broad spectrum of biochemical defects in Dnmt3b-mediated de novo DNA methylation. J. Mol. Biol. 2011, 409, 758-772.

127. De Greef, J.C.; Wang, J.; Balog, J.; den Dunnen, J.T.; Frants, R.R.; Straasheijm, K.R.; Aytekin, C.; van der Burg, M.; Duprez, L.; Ferster, A.; et al. Mutations in ZBTB24 are associated with immunodeficiency, centromeric instability, and facial anomalies syndrome type 2. Am. J. Hum. Genet. 2011, 88, 796-804.

128. Lee, S.U.; Maeda, T. Pok/zbtb proteins: An emerging family of proteins that regulate lymphoid development and function. Immunol. Rev. 2012, 247, 107-119.

129. Weemaes, C.M.; van Tol, M.J.; Wang, J.; van Ostaijen-Ten Dam, M.M.; van Eggermond, M.C.; Thijssen, P.E.; Aytekin, C.; Brunetti-Pierri, N.; van der Burg, M.; Graham Davies, E.; et al. Heterogeneous clinical presentation in icf syndrome: Correlation with underlying gene defects. Eur. J. Hum. Genet. 2013, 21, 1219-1225.

130. Velasco, G.; Walton, E.L.; Sterlin, D.; Hedouin, S.; Nitta, H.; Yuya, I.; Fouyssac, F.; Megarbane, A.; Sasaki, H.; Picard, C.; et al. Germline genes hypomethylation and expression define a molecular signature in peripheral blood of ICF patients: Implications for diagnosis and etiology. Orphanet. J. Rare Dis. 2014, 9, 56.

131. Nitta, H.; Unoki, M.; Ichiyanagi, K.; Kosho, T.; Shigemura, T.; Takahashi, H.; Velasco, G.; Francastel, C.; Picard, C.; Kubota, T.; et al. Three novel ZBTB24 mutations identified in japanese and cape verdean type 2 ICF syndrome patients. J. Hum. Genet. 2013, 58, 455-460.

132. Van den Brand, M.; Flucke, U.E.; Bult, P.; Weemaes, C.M.; van Deuren, M. Angiosarcoma in a patient with immunodeficiency, centromeric region instability, facial anomalies (ICF) syndrome. Am. J. Med. Genet. 2011, 155A, 622-625.

133. Narayan, A.; Tuck-Muller, C.; Weissbecker, K.; Smeets, D.; Ehrlich, M. Hypersensitivity to radiation-induced non-apoptotic and apoptotic death in cell lines from patients with the ICF chromosome instability syndrome. Mutat. Res. 2000, 456, 1-15.

134. Wang, J.; Emadali, A.; le Bescont, A.; Callanan, M.; Rousseaux, S.; Khochbin, S. Induced malignant genome reprogramming in somatic cells by testis-specific factors. Biochim. Biophys. Acta. 2011, $1809,221-225$.

135. Rousseaux, S.; Wang, J.; Khochbin, S. Cancer hallmarks sustained by ectopic activations of placenta/male germline genes. Cell. Cycle 2013, 12, 2331-2332.

136. Rousseaux, S.; Debernardi, A.; Jacquiau, B.; Vitte, A.L.; Vesin, A.; Nagy-Mignotte, H.; Moro-Sibilot, D.; Brichon, P.Y.; Lantuejoul, S.; Hainaut, P.; et al. Ectopic activation of germline and placental genes identifies aggressive metastasis-prone lung cancers. Sci. Transl. Med. 2013, 5,186 ra166.

137. Simpson, A.J.; Caballero, O.L.; Jungbluth, A.; Chen, Y.T.; Old, L.J. Cancer/testis antigens, gametogenesis and cancer. Nat. Rev. Cancer 2005, 5, 615-625.

138. Janic, A.; Mendizabal, L.; Llamazares, S.; Rossell, D.; Gonzalez, C. Ectopic expression of germline genes drives malignant brain tumor growth in Drosophila. Science 2010, 330, 1824-1827.

139. Rudert, F.; Bronner, S.; Garnier, J.M.; Dolle, P. Transcripts from opposite strands of gamma satellite DNA are differentially expressed during mouse development. Mamm. Genome 1995, 6, 76-83. 
140. Efroni, S.; Duttagupta, R.; Cheng, J.; Dehghani, H.; Hoeppner, D.J.; Dash, C.; Bazett-Jones, D.P.; le Grice, S.; McKay, R.D.; Buetow, K.H.; et al. Global transcription in pluripotent embryonic stem cells. Cell Stem Cell 2008, 2, 437-447.

141. Lu, J.; Gilbert, D.M. Proliferation-dependent and cell cycle regulated transcription of mouse pericentric heterochromatin. J. Cell Biol. 2007, 179, 411-421.

142. Eymery, A.; Horard, B.; el Atifi-Borel, M.; Fourel, G.; Berger, F.; Vitte, A.L.; van den Broeck, A.; Brambilla, E.; Fournier, A.; Callanan, M.; et al. A transcriptomic analysis of human centromeric and pericentric sequences in normal and tumor cells. Nucl. Acids Res. 2009, 37, 6340-6354.

143. Ting, D.T.; Lipson, D.; Paul, S.; Brannigan, B.W.; Akhavanfard, S.; Coffman, E.J.; Contino, G.; Deshpande, V.; Iafrate, A.J.; Letovsky, S.; et al. Aberrant overexpression of satellite repeats in pancreatic and other epithelial cancers. Science 2011, 331, 593-596.

144. Alexiadis, V.; Ballestas, M.E.; Sanchez, C.; Winokur, S.; Vedanarayanan, V.; Warren, M.; Ehrlich, M. RNApol-ChIP analysis of transcription from FSHD-linked tandem repeats and satellite DNA. Biochim. Biophys. Acta 2007, 1769, 29-40.

145. Enukashvily, N.I.; Donev, R.; Waisertreiger, I.S.; Podgornaya, O.I. Human chromosome 1 satellite 3 DNA is decondensed, demethylated and transcribed in senescent cells and in A431 epithelial carcinoma cells. Cytogenet. Genome Res. 2007, 118, 42-54.

146. Bergmann, J.H.; Jakubsche, J.N.; Martins, N.M.; Kagansky, A.; Nakano, M.; Kimura, H.; Kelly, D.A.; Turner, B.M.; Masumoto, H.; Larionov, V.; et al. Epigenetic engineering: Histone H3K9 acetylation is compatible with kinetochore structure and function. J. Cell Sci. 2012, 125, 411-421.

147. Zhu, Q.; Pao, G.M.; Huynh, A.M.; Suh, H.; Tonnu, N.; Nederlof, P.M.; Gage, F.H.; Verma, I.M. BRCA1 tumour suppression occurs via heterochromatin-mediated silencing. Nature 2011, 477, 179-184.

148. Jaco, I.; Canela, A.; Vera, E.; Blasco, M.A. Centromere mitotic recombination in mammalian cells. J. Cell Biol. 2008, 181, 885-892.

149. Francastel, C.; Schubeler, D.; Martin, D.I.; Groudine, M. Nuclear compartmentalization and gene activity. Nat. Rev. Mol. Cell Biol. 2000, 1, 137-143.

150. Fisher, A.G.; Merkenschlager, M. Gene silencing, cell fate and nuclear organisation. Curr. Opin. Genet. Dev. 2002, 12, 193-197.

151. Luciani, J.J.; Depetris, D.; Usson, Y.; Metzler-Guillemain, C.; Mignon-Ravix, C.; Mitchell, M.J.; Megarbane, A.; Sarda, P.; Sirma, H.; Moncla, A.; et al. PML nuclear bodies are highly organised DNA-protein structures with a function in heterochromatin remodelling at the G2 phase. J. Cell. Sci. 2006, 119, 2518-2531.

152. Jefferson, A.; Colella, S.; Moralli, D.; Wilson, N.; Yusuf, M.; Gimelli, G.; Ragoussis, J.; Volpi, E.V. Altered intra-nuclear organisation of heterochromatin and genes in ICF syndrome. PLoS One 2010, 5, e11364. 
153. Ehrlich, M.; Tsien, F.; Herrera, D.; Blackman, V.; Roggenbuck, J.; Tuck-Muller, C.M. High frequencies of ICF syndrome-like pericentromeric heterochromatin decondensation and breakage in chromosome 1 in a chorionic villus sample. J. Med. Genet. 2001, 38, 882-884.

(C) 2014 by the authors; licensee MDPI, Basel, Switzerland. This article is an open access article distributed under the terms and conditions of the Creative Commons Attribution license (http://creativecommons.org/licenses/by/3.0/). 